\title{
Estrogen and progestin regulate HIF-1 $\alpha$ expression in ovarian cancer cell lines via the activation of Akt signaling transduction pathway
}

\author{
KEQIN HUA, JINGXIN DIN, QI CAO, WEIWEI FENG, YING ZHANG, \\ LIANGQIN YAO, YAN HUANG, YUQIN ZHAO and YOUJI FENG
}

\author{
Department of Gynecology, The Obstetrics and Gynecology Hospital of Fudan University, Shanghai, P.R. China
}

Received December 12, 2008; Accepted January 22, 2009

DOI: $10.3892 /$ or_00000300

\begin{abstract}
Our previous study revealed that estrogen regulates $\mathrm{nm} 23-\mathrm{H} 1$ expression thus promoting cell migration-invasion via activating PIK3/Akt pathway. In this study, we explored the effect of hormone on hypoxia-inducible factor-1 (HIF$1 \alpha$ ), a key factor in cancer invasion and metastasis, via activation of Akt signaling transduction pathway. We treated two ovarian cancer cell lines ES-2 and SKOV3 with 17ßestradiol, methoxyprogesterone acetate (MPA) only, or hormone combined with and Akt, MAPK pathway inhibitor, or transefected with siRNA targeting Akt sequenced with hormone. Expression of HIF-1 $\alpha$ was measured by Western blotting. We observed the effect of hormone on $\mathrm{nm} 23-\mathrm{H} 1$ expression after the cells were transfected by siRNA targeting HIF- $1 \alpha$ or treated with $\mathrm{CoCl}_{2}$ to induce HIF- $1 \alpha$ overexpression. The $17 ß$-estradiol increased HIF-1 $\alpha$ expression in ovarian cancer cells, and this upregulatory effect was abrogated by Akt inhibitor LY294002 $(\mathrm{P}<0.05)$ and Akt siRNA interference $(\mathrm{P}<0.05)$, but not affected by MAPK inhibitor PD980059 (P>0.05). MPA had the opposite effect. Nm23-H1 protein expression in ES-2 and SKOV3 cells were decreased after treatment with 173 -estradiol $(\mathrm{P}<0.05)$, whereas MPA had the opposite effect. The effect was attenuated by HIF-1 $\alpha$ siRNA $(\mathrm{P}<0.05)$ and enhanced by HIF-1 $\alpha$ overexpression after $\mathrm{CoCl}_{2}$ treatment $(\mathrm{P}<0.05)$. Our data suggest that estrogen and progestin regulate HIF- $1 \alpha$ expression via Akt signaling pathway, affecting $\mathrm{nm} 23-\mathrm{H} 1$ expression in influencing cell metastasis.
\end{abstract}

\section{Introduction}

Ovarian cancers, the third most common gynecological malignancy, and the leading cause of death from gynecological

Correspondence to: Dr Youji Feng or Dr Keqin Hua, Department of Gynecology, The Obstetrics and Gynecology Hospital of Fudan University, 419 FangXie Road, Shanghai 200011, P.R. China E-mail: fengyj4806@sohu.com; huakeqin@126.com

Key words: ovarian cancer, estrogen, progestin, nm23-H1, hypoxia-inducible factor-1 cancer (1), are highly lethal because of the occurrence of occult metastasis within the peritoneal cavity and the fact that they are often detected at an advanced stage, when curative therapy is ineffective. Therefore, great efforts have been made to improve the prognosis of this disease.

The search for factors affecting the progression and behavior of tumors has revealed the importance of the microenvironment surrounding the tumor cells. Peritoneal dissemination is a metastatic process in which the cancer cells detach from the primary tumor, attach to the peritoneum, and re-grow at this site. It is therefore hypothesized that ovarian cancer cells leaving the primary tumor experience lower oxygen levels (2). Hypoxia is known to induce the hypoxia-inducible factor- 1 (HIF-1 $\alpha$ ), which binds to the hypoxia-response elements of various target genes and activates the transcription of these genes controlling glucose transport, angiogenesis, erythropoiesis, and vasomotor regulation, and thus may increase the survival of tumor cells (3). With the progressive and rapid growth of malignant tumors, cancer cells in the ischemic condition are expected to transform to the 'metastatic' phenotype through a reduction in intercellular adhesion as well as an increase in cell motility and invasiveness.

It is generally held that the biological activity of estrogen and progestin is mediated through receptors that act in cell nuclei. However, there is increasing evidence that membraneassociated forms of steroid hormone receptors exist and participate in activation of signaling pathways associated with gene regulation (4).

However, little is known about whether steroids have some effect on HIF-1 $\alpha$ through the activation of the signaling pathway. In this study, we examined the in vitro effect of 17ß-estradiol and methoxyprogesterone acetate (MPA) on the expression of HIF- $1 \alpha$ in ovarian clear cell adenocarcinoma cell line ES-2 and ovarian serous adenocarcinoma cell line SKOV3. Then we treated the cells with Akt and MAPK pathway inhibitor, and then induced Akt gene silencing by RNA interference, and re-evaluated the effect of $17 ß$-estradiol and MPA on the expression of HIF-1 $\alpha$. We induced HIF- $1 \alpha$ gene silencing by RNA interference, and observed whether the alteration of nm23-H1 protein level induced by $17 ß$-estradiol and MPA was abrogated. Finally we treated the cells with $\mathrm{CoCl}_{2}$ to induce HIF-1 $\alpha$ 
overexpression, and re-evaluated the effect of $17 ß$-estradiol and MPA on the expression of nm23-H1. The purpose of the current study was to explore the possible mechanism in ovarian tumor infiltration and metastasis, and to try to block the signal transduction pathway in ovarian cancer progression at a different level, to help in finding new approaches for ovarian cancer prophylaxis and treatment.

\section{Materials and methods}

Cell lines and reagents. The human ovarian clear cell adenocarcinoma cell line ES-2 and ovarian serous adenocarcinoma cell line SKOV3, obtained from the American Type Culture Collection (Manassas, VA), were routinely grown in $5 \% \mathrm{CO}_{2}$ in air at $37^{\circ} \mathrm{C}$. Growth medium was RPMI-1640 medium (Gibco BRL; Gaithersburg, MD) supplemented with $10 \%$ fetal bovine serum.

Estrogen and progestin treatment. 17ß-Estradiol and methoxyprogesterone acetate (MPA) were purchased from Sigma (St. Louis, MO). The ES-2 and SKOV3 cell lines were grown in phenol red-free RPMI-1640 (Sigma) media supplemented with $10 \%$ activated charcoal treated fetal bovine serum (Hyclone; South Logan, UT) for $72 \mathrm{~h}$. Then the medium was removed, and cells were treated with different concentration $\left(10^{-9}, 10^{-8}, 10^{-7}, 10^{-6}\right.$ and $\left.10^{-5} \mathrm{M}\right)$ of $17 ß$-estradiol or MPA for $24 \mathrm{~h}$ or treated with $10^{-6} \mathrm{M} \mathrm{E}_{2}$ or MPA for $30 \mathrm{~min}$, $1,2,4,8,16$ and $24 \mathrm{~h}$. Parallel cultures were treated with vehicle containing only DMSO $(0.01 \%$ vol $)$. Then the level of HIF- $1 \alpha$ protein in ES- 2 and SKOV3 cell lines were detected by Western blotting.

Treatment with Akt or MAPK pathway inhibitors and estrogen or progestin. The ES-2 and SKOV3 cell line were grown in media depleted of steroid for $72 \mathrm{~h}$, then the medium was removed, and medium containing $10^{-6} \mathrm{M} \mathrm{E}_{2}$ or MPA as well as $25 \mu \mathrm{mol} / 1$ Akt pathway inhibitor LY294002 or $25 \mu \mathrm{mol} / 1$ MAPK pathway inhibitor PD980059 was added. Then the level of HIF-1 $\alpha$ protein in ES-2 and SKOV3 cell lines were detected by Western blotting after incubation for $24 \mathrm{~h}$.

Transient siRNA transfection. RNAase pollution was strictly prohibited during siRNA interference. Akt siRNA was procured from Cell Signaling (Danvers, MA). Akt siRNA transfection was performed according to the manufacturer's instructions.

The siRNA sequence targeting HIF-1 $\alpha$ corresponded to the coding region 127-145: 5'-CAGTTGCCACTTCCAC ATA-3'. To construct a vector expressing siRNA for HIF-1 $\alpha$, annealed oligonucleotides containing sense and anti-sense sequences were linked by a hairpin loop: TTCAAGAGA were subcloned into pRNAT-U6.1/Neo, a siRNA expression vector (GenScript Corp., Piscataway, NJ). A random siRNA (5'-ACTACCGTTGTTATAGGTG-3') which does not have any target region in human genes served as negative control.

The ES-2 and SKOV3 cells, cultured in media depleted of steroids for $72 \mathrm{~h}$, were grown to $60 \%$ confluence at the time of transfection. For transfection, cationic lipid complexes were prepared by incubating $6 \mu 1$ of indicated siRNA with
$2 \mu 1$ of oligofectamin reagent (Invitrogen; Carlsbad, CA) in $100 \mu 1$ of serum-free RPMI-1640 for $20 \mathrm{~min}$. The following groups were set: i) siRNA group: the cells were transfected with vector expressing siRNA targeting HIF-1 $\alpha$ (HIF-1 $\alpha$ siRNA); ii) Negative transfection group: the cells were transfected with vector expressing random siRNA (Ctrl siRNA); iii) Control group: the cells were transfected with liposome only. The transfected cells were cultured for $24 \mathrm{~h}$, then the medium was removed and changed, and $48 \mathrm{~h}$ posttransfection medium containing $10^{-6} \mathrm{M} 17 ß$-estradiol or MPA was added for $24 \mathrm{~h}$. Western blotting was conducted to determine indicated protein level.

Cobalt chloride $\left(\mathrm{CoCl}_{2}\right)$ treatment. The ES-2 and SKOV3 cells were incubated in medium containing $10^{-6} \mathrm{M} 17 ß-$ estradiol or MPA for $24 \mathrm{~h}$, and then $\mathrm{CoCl}_{2}$ was added into the medium at a final concentration of $150 \mu \mathrm{M}$. Then Western blotting was conducted to determine level of HIF-1 $\alpha$ protein 3 h later.

Western blot analysis. Cells were lysed in RIPA lysis buffer containing proteinase inhibitor for $30 \mathrm{~min}$. The samples were boiled for $10 \mathrm{~min}$, centrifuged, and the supernatants collected. Each sample $(10 \mu \mathrm{g})$ was loaded on a $10 \%$ SDS-PAGE gel. After electrophoresis, the proteins were transferred onto a polyvinyl difluoride membrane, and the membrane incubated in blocking buffer containing 5\% non-fat dry milk for $1 \mathrm{~h}$ at room temperature. Then the membrane was probed with a primary antibody in blocking buffer [anti-nm23-H1 mouse monoclonal antibody (Santa Cruz Biotechnology Inc.; St. Louis, MO) 1:3000, anti-Akt and anti-pAkt (Ser 473) mouse monoclonal antibodies (Cell Signaling) 1:1000, anti-HIF-1 $\alpha$ mouse monoclonal antibody 1:500 and anti-GAPDH mouse monoclonal antibody (Sigma) 1:3000 as the internal marker] overnight at $4^{\circ} \mathrm{C}$, followed by probing with anti-mouse IgHRP conjugates (Amersham Biosciences; Buckinghamshire, UK) in blocking buffer (at a dilution of 1:3000) for $2 \mathrm{~h}$ at $37^{\circ} \mathrm{C}$. Immunocomplexes were then visualized using ECL as recommended by the manufacturer (Amersham Biosciences).

Statistical analysis. Data were analyzed with Student's t-test by software SPSS10.0. Studies were performed in triplicate with the results expressed as mean $\pm \mathrm{SD}$ as appropriate. Differences were considered to be significant at $\mathrm{P}<0.05$.

\section{Results}

Impact of $17 \beta$-estradiol and MPA on HIF-1 $\alpha$ protein expression in ES-2 and SKOV3 cells. Western blots showed that HIF- $1 \alpha$ protein expression in ES- 2 and SKOV3 cells was increased after treatment with 17ß-estradiol, and the effect was both dose- and time-dependent. The level of HIF-1 $\alpha$ protein in ES-2 and SKOV3 cells began to increase when treated with $10^{-9} \mathrm{~mol} / 1 \mathrm{1} 13$-estradiol, and reached peak for $10^{-6} \mathrm{~mol} / \mathrm{l}$ 17ß-estradiol, for $24 \mathrm{~h}$. For time course, the level of HIF-1 $\alpha$ protein in ES-2 and SKOV3 cells increased obviously when treated with $10^{-6} \mathrm{~mol} / 1173$-estradiol, for 24 or $16 \mathrm{~h}(\mathrm{P}<0.05)$, and HIF-1 $\alpha$ protein expression rose to the peak value at $24 \mathrm{~h}$ in ES-2 and SKOV3 cells (Fig. 1A and B). 
A 虫|

\section{๖े}

Con $(\mathrm{mol} / \mathrm{l})$
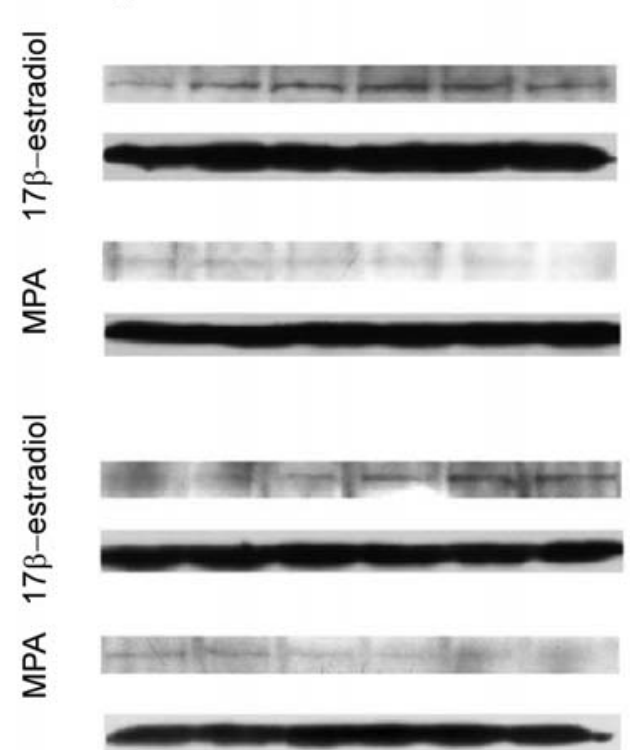

control $10^{-9} \quad 10^{-8} \quad 10^{-7} \quad 10^{-6} \quad 10^{-5}$
B
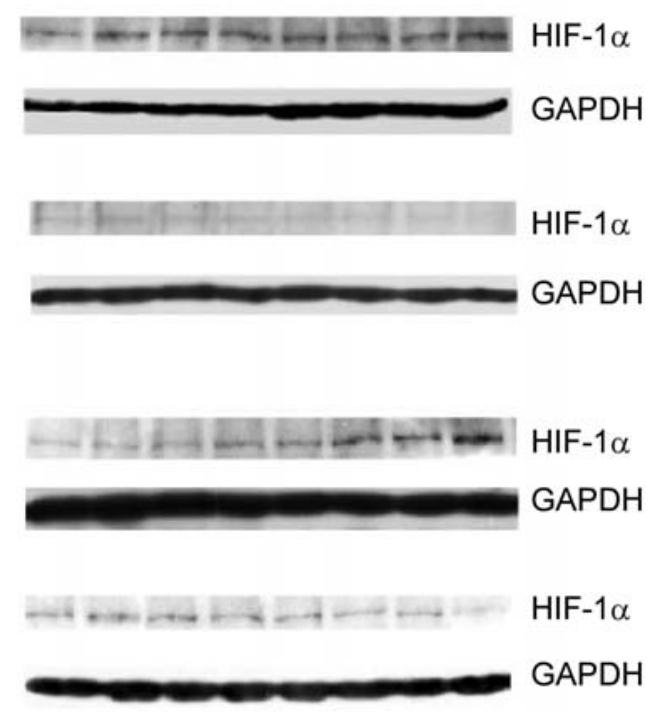

control $0.5 \quad 1 \quad 2 \quad 4 \quad 8 \quad 16 \quad 24 \quad$ Time (h)

Figure 1. Estrogen increased HIF-1 $\alpha$ expression in ovarian cancer cells, whereas progestin had the opposite effect. 17ß-estradiol and MPA differentially altered the expression of HIF-1 $\alpha$ in a dose- (A) and time- (B) dependent manner in ES- 2 and SKOV 3 cells. HIF-1 $\alpha$ protein levels were determined by Western blot analysis with anti-HIF-1 $\alpha$ antibody. GAPDH was used as loading control.

Western blots showed that HIF-1 $\alpha$ protein expression in ES-2 and SKOV3 cells was downregulated after treated with MPA, and the effect was both dose- and time-dependent. The level of HIF-1 $\alpha$ protein in ES-2 and SKOV3 cells began to decrease when treated with $10^{-7} \mathrm{~mol} / 1$ or $10^{-6} \mathrm{~mol} / 1 \mathrm{MPA}$ for $24 \mathrm{~h}(\mathrm{P}<0.05)$. For time course, the level of HIF-1 $\alpha$ protein in ES-2 and SKOV3 cells decreased obviously when treated with $10^{-6} \mathrm{~mol} / 1 \mathrm{MPA}$ for $24 \mathrm{~h}(\mathrm{P}<0.05)$, and HIF- $1 \alpha$ protein expression reduced to the peak value at $24 \mathrm{~h}$ in ES-2 and SKOV3 cells (Fig. 1A and B).

Effect of Akt signaling inhibitor on change of HIF-1a protein expression in ES-2 and SKOV3 cells induced by $E_{2}$ or MPA. HIF- $1 \alpha$ protein expression in ES-2 cells increased after treatment with $17 \beta$-estradiol $(\mathrm{P}<0.05)$, and this upregulation of HIF- $1 \alpha$ protein by $17 \beta$-estradiol was abrogated by Akt inhibitor LY294002 $(\mathrm{P}<0.05)$ and was not affected by MAPK inhibitor PD980059 ( $\mathrm{P}>0.05)$. HIF-1 $\alpha$ protein expression in ES-2 cells decreased after treatment with MPA $(\mathrm{P}<0.05)$, and this downregulation of HIF- $1 \alpha$ protein by MPA was not affected obviously by Akt inhibitor LY294002 or MAPK inhibitor PD980059 (P>0.05) (Fig. 2A).

Similarly, HIF-1 $\alpha$ protein expression in SKOV3 cells increased after treatment with $17 \beta$-estradiol $(\mathrm{P}<0.05)$, and this upregulation of HIF- $1 \alpha$ protein by 173 -estradiol was also abrogated by Akt inhibitor LY294002 $(\mathrm{P}<0.05)$ and was not affected by MAPK inhibitor PD980059 (P>0.05). HIF-1 $\alpha$ protein expression in SKOV3 cells decreased after treatment with MPA $(\mathrm{P}<0.05)$, and this downregulation of HIF-1 $\alpha$ protein by MPA was abrogated by Akt inhibitor LY294002 $(\mathrm{P}<0.05)$, but was not affected by MAPK inhibitor PD980059 (P>0.05) (Fig. 2A).
Effect of Akt siRNA interference on change of HIF-1a protein expression in ES-2 and SKOV3 cells induced by $E_{2}$ or MPA. As 17ß-estradiol- as well as MPA-induced HIF- $1 \alpha$ expression was abrogated by inhibition of Akt pathway, we further investigated the impact of Akt on hormone induced HIF- $1 \alpha$ expression after knocking down Akt using siRNA inter-ference approach (Fig. 2B).

Similarly, HIF-1 $\alpha$ protein expression in ES-2 and SKOV3 cells increased after treatment with $17 ß$-estradiol, and this upregulation of HIF- $1 \alpha$ protein by $17 \beta$-estradiol was also abrogated by Akt siRNA interference $(\mathrm{P}<0.05)$ and was not affected by random siRNA transfection $(\mathrm{P}>0.05)$. HIF- $1 \alpha$ protein expression in ES-2 and SKOV3 cells induced after treatment with MPA, and this downregulation of HIF- $1 \alpha$ protein by MPA was also abrogated by Akt siRNA interference $(\mathrm{P}<0.05)$, and was not affected by random siRNA trans-fection ( $\mathrm{P}>0.05)$ (Fig. 2B).

Effect of HIF-1a siRNA interference on change of nm23-H1 protein expression in ES-2 and SKOV3 cells induced by $17 \beta-$ estradiol or MPA

Efficiency of HIF-1a siRNA transfection in ES-2 and SKOV3 cells. The efficiency of siRNA transfection was detected by fluorescence microscope. The green fluorescence produced by GFP, which was carried by the vector pRNAT-U6.1/Neo, was observed under fluorescence microscope in cells of the siRNA group and of the negative transfection group, but was not observed in the control group transfected with only liposome. The number of all the cells and the cells producing green fluorescence was counted in 4 different fields under a light microscope at x200 magnification, and the efficiency of siRNA transfection was calculated by the number of cells 


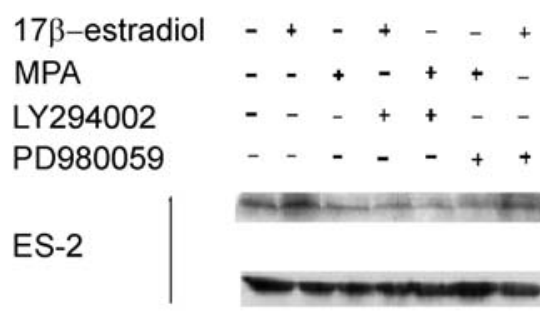

SKOV3
A

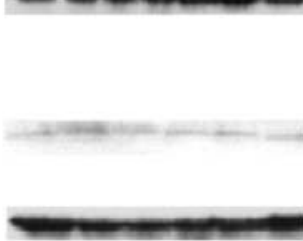

B

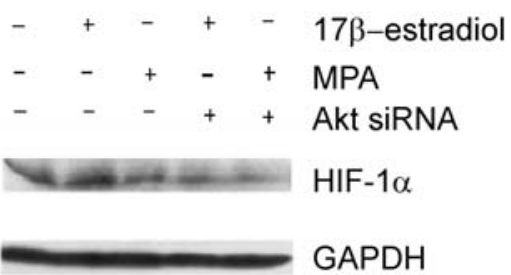

HIF-1 $\alpha$

Figure 2. The PIK3/AKT pathway was involved in hormone regulation of HIF-1 $\alpha$ expression. (A) HIF-1 $\alpha$ protein expression was assessed by Western blot analysis in ES-2 and SKOV3 cells treated with 17B-estradiol, MPA, and hormone combined with LY294002, PD980059(B) or treated with 17ß-estrogen, MPA, siAKT combined with 17ß-estradiol, MPA. GAPDH served as the loading control.

A

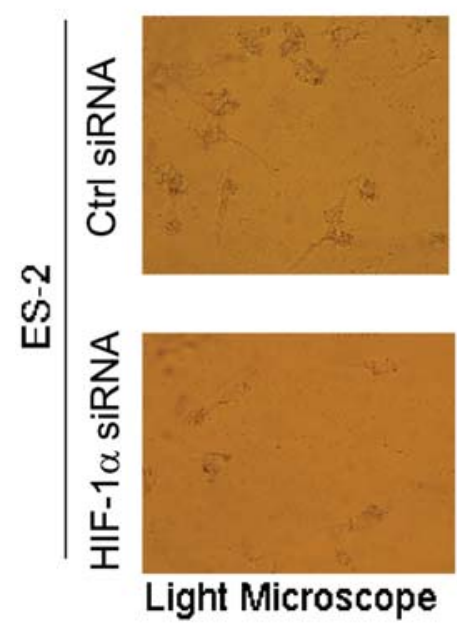

B

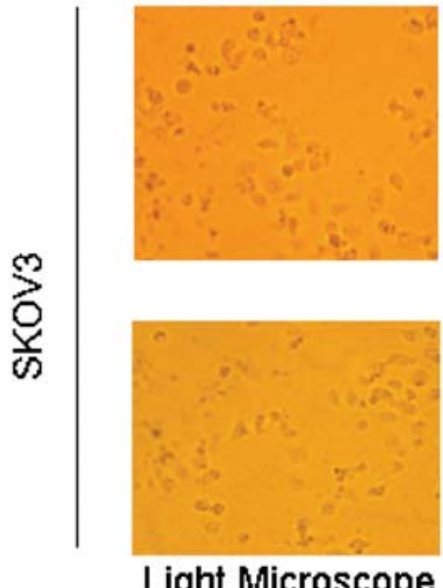

Light Microscope
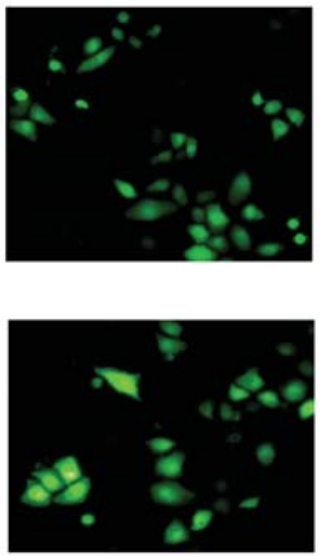

Fluo Microscope

Figure 3. Microscopic analysis of ES-2 and SKOV3 cells transfected with siRNA targeted to HIF-1 $\alpha$ using normal light microscope or fluorescence microscope separately. Random siRNA served as control (x200 magnification).

producing green fluorescence/the number of all the cells. The efficiency of siRNA transfection was $55.6 \%$ in ES-2 cells, and the efficiency of siRNA transfection was $78.5 \%$ in SKOV3 cells (Fig. 3).

The effect of HIF-1a siRNA on HIF-1a protein expression. Western blot analysis showed that HIF-1 $\alpha$ protein expression in ES-2 and SKOV3 cells was abrogated by the introduction of HIF-1 $\alpha$ siRNA, but not affected by ctrl siRNA $(\mathrm{P}<0.05)$ (Fig. 4A).

Effect of HIF-1a siRNA interference on change of nm23-HI protein expression. $\mathrm{Nm} 23-\mathrm{H} 1$ protein expression in ES-2 and SKOV3 cells decreased after treatment with 17ß-estradiol $(\mathrm{P}<0.05)$, and this downregulation of $\mathrm{nm} 23-\mathrm{H} 1$ protein by $17 ß$-estradiol was attenuated by HIF- $1 \alpha$ siRNA $(\mathrm{P}<0.05)$ and was not affected by control siRNA $(\mathrm{P}>0.05)$. Nm23-H1 protein expression in ES-2 and SKOV3 cells increased after treatment with MPA $(\mathrm{P}<0.05)$, and this upregulation of $\mathrm{nm} 23-\mathrm{H} 1$ protein by MPA was attenuated by HIF- $1 \alpha$ siRNA $(\mathrm{P}<0.05)$ and was not affected by control siRNA $(\mathrm{P}>0.05)$ (Fig. 5A).

Effect of HIF-1 1 overexpression on $n m 23-H 1$ protein expression in ES-2 and SKOV3 cells induced by 17ß-estradiol or $M P A$

The overexpression effect of $\mathrm{CoCl}_{2}$ on $\mathrm{HIF}$-1 $\alpha$ protein. HIF- $1 \alpha$ protein level in ES-2 and SKOV3 cells was obviously elevated after treatment with $\mathrm{CoCl}_{2}(\mathrm{P}<0.01)$ (Fig. 4B).

Effect of HIF-1a overexpression on change of nm23-H1 protein expression. $\mathrm{Nm} 23-\mathrm{H} 1$ protein expression in ES-2 and SKOV3 cells decreased after treatment with $17 ß$-estradiol and this downregulation of $\mathrm{nm} 23-\mathrm{H} 1$ protein by $17 \mathrm{~B}$-estradiol 
A

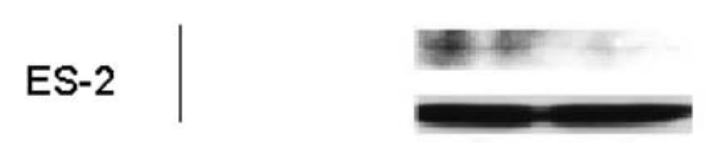

SKOV3
B

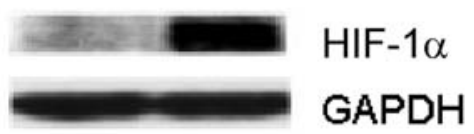

Figure 4. HIF-1 $\alpha$ protein expression was affected by HIF-1 $\alpha$ siRNA and $\mathrm{CoCl}_{2}$. Cells were transiently transfected with HIF-1 $\alpha$ siRNA (A) and treated with $\mathrm{CoCl}_{2}$. (B) Total HIF-1 $\alpha$ expression was detected by Western blot analysis, normalized to GAPDH as a total protein loading control.

A

Ctrl siRNA
HIF-1 $\alpha$ siRNA
$17 \beta$-estradiol
MPA

ES-2

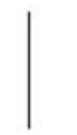

SKOV 3
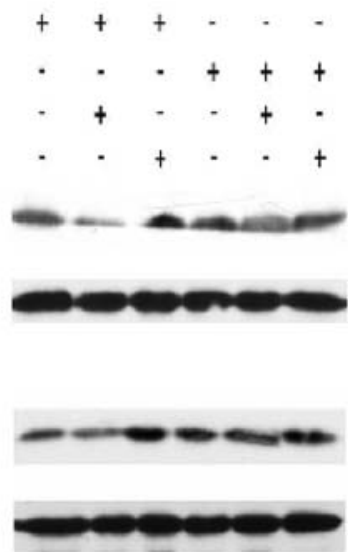

B

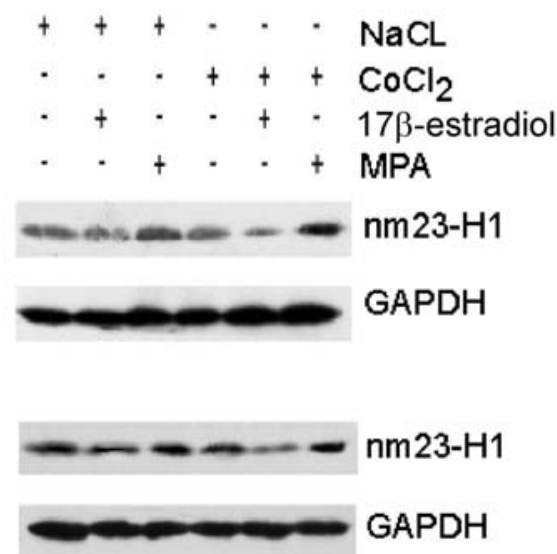

Figure 5. HIF-1 $\alpha$ was involved in hormone regulation of nm23-H1 expression. Nm23-H1 protein expression was assessed by Western blot analysis in ES-2 and SKOV3 cells treated with HIF- $1 \alpha$ siRNA, Ctrl siRNA and HIF-1 $\alpha$ siRNA combined with $17 ß$-estradiol, $\mathrm{MPA}(\mathrm{A})$ or treated with $\mathrm{CoCl}{ }_{2}, \mathrm{NaCl}$ and $\mathrm{CoCl}{ }_{2}$ combined with 17ß-estradiol, MPA (B). GAPDH served as the loading control.

was enhanced by HIF-1 $\alpha$ overexpression after $\mathrm{CoCl}_{2}$ treatment $(\mathrm{P}<0.05)$ and was not affected by $\mathrm{NaCl}$ treatment $(\mathrm{P}>0.05)$. Nm23-H1 protein expression in ES-2 and SKOV3 cells increased after treatment with MPA, and this upregulation of $\mathrm{nm} 23-\mathrm{H} 1$ protein by MPA was enhanced by HIF- $1 \alpha$ overexpression after $\mathrm{CoCl}_{2}$ treatment $(\mathrm{P}<0.05)$ and was not affected by $\mathrm{NaCl}$ treatment $(\mathrm{P}>0.05)$ (Fig. 5B).

\section{Discussion}

The effect of HIF-1 $\alpha$ on ovarian tumor progression. HIF-1 $\alpha$ is sensitive to oxygen levels, and, under normoxic conditions, several praline residues are hydroxylated by distinct prolyl hydroxylases and rapidly degraded via ubiquitin-proteasome pathway (5). However, under hypoxic conditions, HIF-1 $\alpha$ subunit is stabilized and translocates into the nucleus, thereby homodimerizing with HIF-1ß and binding to hypoxia- response element (HRE) DNA sequence on the promoter region of HIF-1 target genes to activate their transcription (6). In addition to this hypoxia-dependent mechanism, recent studies have demonstrated non-hypoxic pathways for regulation of HIF- $1 \alpha$ activity $(7,8)$ and multiple regulatory mechanisms of HIF-1 $\alpha$ protein level, may enable cells to adapt to diverse alteration of environments and preserve homeostasis in a tissue-dependent manner. For example, receptor-mediated regulation of HIF-1 $\alpha$ expression is thought to be cell and signal specific, and a number of studies have suggested that receptor-mediated factors such as growth factors, hormones, and cytokines induce HIF-1 $\alpha$ protein expression through various signaling (9-16).

In this study, we first reported that $17 ß$-estradiol increased HIF- $1 \alpha$ expression, and MPA decreased HIF- $1 \alpha$ expression in ovarian cell lines ES-2 and SKOV3, and that both effect was dose- and time-dependent. In another study, we found 
17ß-estradiol increased Akt expression, and MPA exerted the reverse effect. To assess the role of signal transduction pathway in regulation of estrogen and progestin on HIF-1 $\alpha$ expression, we treated the cells with Akt and MAPK signal transduction pathway inhibitor and re-evaluated the effect of $17 ß$-estradiol and MPA on the expression of HIF-1 $\alpha$, and found that the change of HIF-1 $\alpha$ expression induced by $173-$ estradiol and MPA was abrogated by the Akt signaling inhibitor. We concluded that 17ß-estradiol upregulated the expression of HIF- $1 \alpha$ via activation of the Akt phosphorylation signaling, and MPA downregulated the expression of HIF-1 $\alpha$ via repression of the Akt phosphorylation signaling. This result was further supported by Akt gene silencing induced by RNA interference. Thus it is suggested that the intracellular signal transduction pathway PI3K-Akt signaling was an upstream signal in steroid regulation on HIF-1 $\alpha$ expression, while the extracellular regulated kinase MAPK signaling was not involved in the steroid effect on HIF-1 $\alpha$ expression in ES-2 and SKOV3 cells. The results of the current study help to better understand the regulation and the possible mechanisms of the effect of steroids on HIF-1 $\alpha$ expression in ES-2 and SKOV 3 cells. This result confirms a study demonstrating that protein phosphorylation might participate in the signal transduction pathways induced by hypoxia (17) .

The regulatory effect of steroids on $\mathrm{nm} 23-\mathrm{H} 1$ is mediated by HIF-1 $\alpha$. It is likely that malignant tumor cells exhibit uncontrolled growth, eventually outstripping their blood supply, and are exposed to sublethal ischemia, which itself may have the effect of stimulating invasiveness and angiogenesis. The transcription factor HIF-1 is generally believed to be a central regulator of the cellular response to hypoxia (4). HIF-1 induces expression of the genes essential for adaption to hypoxia including those for erythropoietin, glucose transporters, glycolytic enzymes, and vascular endothelial growth factor (VEGF), eliciting successful homeostatic regulation under hypoxic conditions.

It was reported that a combination of HIF- $1 \alpha$ and chemotherapy could provide a more effective approach for inhibiting tumor growth in ovarian cancer than chemotherapeutic drug alone (18), thus it was suggested that HIF inhibitor rapamycin inhibited tumor growth, and that HIF promoted infiltration and metastasis of tumor cells.

However, little is known about the functional relationship of HIF- $1 \alpha$ with tumor metastasis. The results of a recent study (19) showed that the downregulation of $\mathrm{nm} 23-\mathrm{H} 1$ protein induced by 17ß-estradiol and the upregulation of $\mathrm{nm} 23-\mathrm{H} 1$ protein induced by MPA in ES-2 and SKOV3 cells was enhanced by HIF-1 $\alpha$ overexpression, and attenuated by HIF- $1 \alpha$ siRNA transfection. These findings suggest that HIF- $1 \alpha$ might be an upstream signal participating in the regulation of $\mathrm{nm} 23-\mathrm{H} 1$.

Therefore, steroid-HIF-1 $\alpha-\mathrm{nm} 23-\mathrm{H} 1$ systems might be possible candidates for molecular targeting in the future treatment of malignant ovarian tumors. The development and progression of malignant tumors is a complicated process involving the participation of multiple factors, procedures and steps, as well as the participation of the regulation of multiple oncogenes and anti-oncogenes. Further studies on the molecular mechanism involved in peritoneal dissemination of ovarian tumor cells are needed to develop novel molecular therapeutic targets for ovarian carcinomas.

\section{References}

1. Chien JR, Aletti G, Bell DA, Keeney GL, Shridhar V and Hartmann LC: Molecular pathogenesis and therapeutic targets in epithelial ovarian cancer. J Cell Biochem 102: 1117-1129, 2007.

2. Papandreou I, Krishna C, Kaper F, Cai D, Giaccia AJ and Denko NC: Anoxia is necessary for tumor cell toxicity caused by a low-oxygen environment. Cancer Res 65: 3171-3178, 2005.

3. Galanis A, Pappa A, Giannakakis A, Lanitis E, Dangaj D and Sandaltzopoulos R: Reactive oxygen species and HIF-1 signalling in cancer. Cancer Lett 266: 12-20, 2008.

4. Quintero M, Mackenzie N and Brennan PA: Hypoxia-inducible factor 1 (HIF-1) in cancer. Eur J Surg Oncol 30: 465-468, 2004.

5. Semenza GL: Hydroxylation of HIF-1: oxygen sensing at the molecular leve. Physiology 119: 176-182, 2004.

6. Schofield CJ and Ratcliffe PJ: Oxygen sensing by HIF hydroxylases. Cell Biol 5: 343-354, 2004.

7. Treins C, Giorgetti-Peraldi S, Murdaca J, Semenza GL and Van Obberghen E: Insulin stimulates hypoxia-inducible factor 1 through a phosphatidylinositol 3-kinase/target of rapamycindependent signaling pathway. J Biol Chem 277: 27975-27981, 2002.

8. Bilton RL and Booker GW: The subtle side to hypoxia inducible factor $(\mathrm{HIF} \alpha)$ regulation. Eur J Biol Chem 270: 791-798, 2003

9. Fang Gao N, Nester RA and Sarkar MA: 4-Hydroxy estradiol but not 2-hydroxy estradiol induces expression of hypoxiainducible factor 1alpha and vascular endothelial growth factor A through phosphatidylinositol 3-kinase/Akt/FRAP pathway in OVCAR-3 and a 2780-CP70 human ovarian carcinoma cells. Toxicol Appl Pharmacol 196: 124-135, 2004.

10. Fang J, Xia C, Cao Z, Zheng JZ, Reed E and Jiang BH: Apigenin inhibits VEGF and HIF-1 expression via PI3K/AKT/ p70S6K1 and HDM2/p53 pathways. FASEB J 19: 342-353, 2005.

11. Alam H, Maizel ET, Park Y, Ghaey S, Feiger ZJ, Chandel NS and Hunzicker-Dunn M: Follicle-stimulating hormone activation of hypoxia-inducible factor-1 by the phosphatidylinositol 3-kinase/AKT/Ras homolog enriched in brain (Rheb)/mammalian target of rapamycin (mTOR) pathway is necessary for induction of select protein markers of follicular differentiation. J Biol Chem 279: 19431-19440, 2004.

12. Blouin CC, Page EL, Soucy GM and Richard DE: Hypoxic gene activation by lipopolysaccharide in macrophages: implication of hypoxia-inducible factor 1 $\alpha$. Blood 103: 1124-1130, 2004.

13. Xu Q, Briggs J, Park S, Niu G, Kortylewski M, Zhang S, Gritsko T, Turkson J, Kay H, Semenza GL, Cheng JQ, Jove R and Yu H: Targeting Stat3 blocks both HIF-1 and VEGF expression induced by multiple oncogenic growth signaling pathways. Oncogene 24: 5552-5560, 2005.

14. Treins C, Giorgetti-Peraldi S, Murdaca J, Monthouël-Kartmann MN and Van Obberghen E: Regulation of hypoxia-inducible factor (HIF)-1 activity and expression of HIF hydroxylases in response to insulin-like growth factor I. Mol Endocrinol 119: 1304-1317, 2005.

15. Fukuda R, Kelly B and Semenza GL: Vascular endothelial growth factor gene expression in colon cancer cells exposed to prostaglandin E2 is mediated by hypoxia-inducible factor 1 . Cancer Res 63: 2330-2334, 2003.

16. Liu LZ, Hu XW, Xia C, He J, Zhou Q, Shi X, Fang J and Jiang BH: Reactive oxygen species regulate epidermal growth factor-induced vascular endothelial growth factor and hypoxiainducible factor-1alpha expression through activation of AKT and P70S6K1 in human ovarian cancer cells. Free Radic Biol Med 41: 1521-1533, 2006.

17. Mottet D, Dumont V, Deccache Y, Demazy C, Ninane N, Raes M and Michiels C: Regulation of hypoxia-inducible factor-1alpha protein level during hypoxic conditions by the phosphatidylinositol 3-kinase/Akt/glycogen synthase kinase 3beta pathway in HepG2 cells. J Biol Chem 278: 31277-31285, 2003.

18. Jiang $\mathrm{H}$ and Feng Y: Hypoxia-inducible factor 1alpha (HIF-1 alpha) correlated with tumor growth and apoptosis in ovarian cancer. Int J Gynecol Cancer 16: 405-412, 2006.

19. Hua KQ, Feng WW, Cao Q, Zhou XR and Feng YJ: Estrogen and progestin regulate metastasis through the PI3K/AKT pathway in human ovarian cancer. Int J Oncol 33: 959-969, 2008 . 